\title{
Molecular prevalence and subtyping of Cryptosporidium hominis among captive long-tailed macaques (Macaca fascicularis) and rhesus macaques (Macaca mulatta) from Hainan Island, southern China
}

Wei Zhao ${ }^{1,3}$, Huanhuan Zhou ${ }^{1,2,3}$, Hairong Jin ${ }^{4}$, Meicen Liư ${ }^{4}$, Mingyan Qiu 4 , Lihua Li ${ }^{1}$, Feifei Yin ${ }^{2,3}$, Jasper Fuk-Woo Chan ${ }^{2,5}$ and Gang Lu L, $^{1,3^{*}}$

\begin{abstract}
Background: Cryptosporidium is an important zoonotic parasite that is commonly found in non-human primates (NHPs). Consequently, there is the potential for transmission of this pathogen from NHPs to humans. However, molecular characterization of the isolates of Cryptosporidium from NHPs remains relatively poor. The aim of the present work was to (i) determine the prevalence; and (ii) perform a genetic characterization of the Cryptosporidium isolated from captive Macaca fascicularis and M. mulatta on Hainan Island in southern China.

Methods: A total of 223 fresh fecal samples were collected from captive M. fascicularis $(n=193)$ and M. mulatta $(n=30)$. The fecal specimens were examined for the presence of Cryptosporidium spp. by polymerase chain reaction (PCR) and sequencing of the partial small subunit (SSU) rRNA gene. The Cryptosporidium-positive specimens were subtyped by analyzing the 60-kDa glycoprotein (gp60) gene sequence.

Results: Cryptosporidium spp. were detected in 5.7\% (11/193) of M. fascicularis. All of the 11 Cryptosporidium isolates were identified as $C$. hominis. Subtyping of nine of these isolates identified four unique gp60 subtypes of $C$. hominis. These included laA20R3a $(n=1)$, IOA17a $(n=1)$, loA17b $(n=1)$, and liA17 $(n=6)$. Notably, subtypes laA20R3a, loA17a, and IoA17b were novel subtypes which have not been reported previously.

Conclusions: To our knowledge, this is the first reported detection of Cryptosporidium in captive M. fascicularis from Hainan Island. The molecular characteristics and subtypes of the isolates here provide novel insights into the genotypic variation in C. hominis.
\end{abstract}

Keywords: Cryptosporidium, Macaca fascicularis, Macaca mulatta, Gp60, SSU rRNA

\section{Background}

Cryptosporidium is a protozoan belonging to the phylum Apicomplexa. The parasite is the causative agent of cryptosporidiosis, the clinical signs of which include diarrhea, malabsorption and wasting in humans [1].

\footnotetext{
*Correspondence: luganghn@aliyun.com; ganglu2018@126.com

1 Department of Pathogenic Biology, Hainan Medical University, Haikou,

Hainan, China

Full list of author information is available at the end of the article
}

Cryptosporidiosis is a significant threat to immunocompromised patients, especially among patients with human immunodeficiency virus (HIV)/ Acquired Immunodeficiency Syndrome (AIDS) in whom the mortality rate is high [2]. Cryptosporidiosis in children is associated with malnutrition and poor growth and is one of the most important causes of diarrhea-associated death among young children in developing countries [3]. In addition to humans, epidemiological evidence showed that Cryptosporidium is capable of infecting more than 260 
vertebrate species, including mammals, birds, reptiles, fish and amphibians $[4,5]$. Cryptosporidium oocysts are ubiquitous in the environment and more than 550 waterborne and food-borne outbreaks of cryptosporidiosis have been reported globally, with the sources of infection linked to drinking or recreational water, fruits, vegetables, or cow's milk [6, 7]. Because of the clinical and public health importance of Cryptosporidium, this protozoan is considered as a category B list priority pathogen by the National Institutes of Health (NIH) of the USA and the fifth most important food-borne parasite by the Food and Agriculture Organization (FAO)/World Health Organization (WHO) Expert Committee [8, 9].

Extensive genetic variations have been reported within the genus Cryptosporidium. Thus far, 38 species and more than 40 genotypes have been identified [10]. Over 20 species or genotypes of Cryptosporidium have been found in humans [10]. Most human-pathogenic Cryptosporidium species and genotypes have also been found in animals [10]. The accurate identification of Cryptosporidium in animals at the species and/or genotype level is essential for the assessment of the potential zoonotic sources of infection among humans [10]. The two most common species detected in humans, C. parvum and C. hominis, are responsible for $>90 \%$ of human cases of cryptosporidiosis worldwide, and are responsible for almost all outbreaks of cryptosporidiosis [11]. While $C$. parvum is generally accepted to be a zoonotic pathogen and it was widely accepted that cases of $C$. hominis were transmitted from human-to-human, but recent reports have shown that $C$. hominis are more commonly found in animals (including NHPs, horses, and donkeys) [10]. Molecular subtyping has been increasingly used to study the transmission of Cryptosporidium in human and animals. Several subtypes of $C$. hominis and $C$. parvum have been identified based on the $60 \mathrm{kDa}$ glycoprotein (gp60) gene sequence, which is the most commonly used genetic locus for the subtyping of Cryptosporidium [12]. These subtyping results have shown that the same subtypes of C. parvum may be found in humans and their epidemiologically-linked animals, suggesting that infected animals are a major source of human infection $[13,14]$.

Among animals, NHPs, due to their high level of genetic homology to humans, are invaluable experimental models for biomedical research. In addition, they may be susceptible to infection with numerous human pathogens including Cryptosporidium [15]. More than 40 studies from 12 countries have been published describing infection of NHPs with Cryptosporidium. However, few studies have included data on genotyping [16]. Eight species of Cryptosporidium have been reported in nonhuman primates including $C$. hominis, C. parvum, $C$. felis, C. muris, C. ubiquitum, C. meleagridis, C. bovis and C. andersoni $[15,17-29]$. Interestingly, all of these species have been detected in humans as well. Macaca fascicularis (long-tailed macaque) and M. mulatta (rhesus macaque) are two common species of NHPs which live in close proximity to many humans, and frequently interact with human communities in many locations, including China. The health of $M$. fascicularis and M. mulatta are therefore an important public health issue. The aim of the present study was to determine the prevalence of natural Cryptosporidium infection in captive M. fascicularis and M. mulatta. The sampled animals were from a facility that breeds NHPs for research purposes in Hainan Island, China. The second aim of this study was to subtype the $C$. hominis isolates sequencing the gp60 gene.

\section{Methods}

\section{Collection of fecal specimens}

A total of 223 fresh fecal samples were collected from $193 \mathrm{M}$. fascicularis and $30 \mathrm{M}$. mulatta between July and August 2018 at the breeding base of experimental primates of Hainan Jingang Biological Technology Co., Ltd., at Haikou, Hainan, China. This breeding base of experimental primate was established in 2003. At the time of sample collection, the facility housed over 10,000 animals. All M. fascicularis in the facility were reared in groups, with the exception of infants, who were housed alone with their mothers until weaning (at approximately 8 months of age). Young animals aged $1-2$ years were kept in individual cages for a quarantine period of 30 days before being sold to research laboratories. Two groups of $M$. fascicularis were sampled in this study: one group contained 125 weaned (one year-old) M. fascicularis who were housed individually, and the other group contained 68 adult $M$. fascicularis (> five years of age) who were housed in groups of 20-30 animals per cage for breeding purposes. For singly housed animals, fresh feces were collected from the floor of the cages immediately after defecation. For animals housed in groups, fresh fecal deposits were collected from the ground in the early morning, as the floors of animal houses were cleaned every evening. To minimize the chance of duplicate sampling of animals, only one fecal specimen was collected at one location of the ground in each animal pen within any house each time. The M. mulatta sampled in this study were all $>10$ years-old and were maintained in individual cages for research laboratories. All the fecal samples were put into individual plastic bags marked with the age and health status of each animal. All samples were transported to our laboratory in a cooler with ice packs within $24 \mathrm{~h}$ and were stored at $4{ }^{\circ} \mathrm{C}$ until the time of processing. 


\section{DNA extraction}

Prior to DNA extraction, all fecal specimens were processed by filtering through mesh to remove large solids, concentrating, and washing three times with distilled water by centrifugation for $10 \mathrm{~min}$ at $1500 \times g$. Genomic DNA was extracted using a QIAamp DNA Stool Mini Kit (Qiagen, Hilden, Germany) according to the manufacturer's instructions. DNA was eluted in $200 \mathrm{ml}$ of Buffer AE and stored at $-20^{\circ} \mathrm{C}$ prior to use in PCR analysis.

\section{Cryptosporidium genotyping and subtyping}

All DNA preparations were tested for the presence of Cryptosporidium spp. by nested PCR amplification of an 830 bp nucleotide fragment of the $S S U$ rRNA gene, using the primers previously described by Xiao et al. [30]. The cycling parameters for the PCR reactions were optimized and used as follows: $94{ }^{\circ} \mathrm{C}$ for $3 \mathrm{~min}$ and 35 cycles of $95{ }^{\circ} \mathrm{C}$ for $30 \mathrm{~s}$, $55^{\circ} \mathrm{C}$ for $30 \mathrm{~s}$, and $72{ }^{\circ} \mathrm{C}$ for $90 \mathrm{~s}$, followed by a final extension step at $72{ }^{\circ} \mathrm{C}$ for $7 \mathrm{~min}$. TaKaRa TaqDNA Polymerase (TaKaRa Bio Inc., Tokyo, Japan) was used for all PCR reactions. A negative control with no DNA was included in all PCR tests. Subtyping of Cryptosporidium-positive samples was conducted by nested PCR amplification of fragments of approximately $800-850 \mathrm{bp}$ of the $g p 60$ gene [31].

\section{Sequence analysis}

All PCR products were sequenced using PCR primers for each locus on an ABI PRISMTM 3730 DNA Analyzer (Applied Biosystems, Carlsbad, CA, USA), in conjunction with the BigDye Terminator v3.1 Cycle Sequencing kit (Applied Biosystems, USA). The accuracy of the sequencing data was confirmed by sequencing in both directions. Nucleotide sequences obtained in the present study were subjected to BLAST searches (http://www.ncbi.nlm.nih. gov/blast/) and then analyzed and aligned with each other and the published reference sequences of Cryptosporidium in GenBank, using ClustalX 1.81 (http://www.clustal.org/).

\section{Statistical analysis}

Differences in infection rates among different groups of animals were compared using the Chi-square test or Fisher's exact test in SPSS 17.0. $P<0.05$ was considered to be statistically significant.

\section{Results}

Prevalence rate of Cryptosporidium spp. in M. fascicularis and M. mulatta

Of the 223 fecal samples tested, 11 (4.9\%) were found to be positive for Cryptosporidium by PCR (Table 1). All 11 Cryptosporidium-positive samples were from $M$. fascicularis $(11 / 193,5.7 \%)$ and none was found in M. mulatta $(0 / 30,0 \%)$, although this did not reach statistical significance $(P=0.37)$. It was also observed that only young $M$. fascicularis were infected with Cryptosporidium. Furthermore, infection was observed in both males and females, as well as in both diarrhea and non-diarrhea groups. Whereas differences in the Cryptosporidium infection rates between female $(6.5 \% ; 6 / 92)$ and male $(5.0 \% ; 5 / 101)$ $M$. fascicularis were not significant $(P>0.05)$, positive animals with diarrhea $(13.8 \% ; 4 / 29)$ were significantly higher than without diarrhea $(4.3 \%$; $7 / 164)(P=0.04)$.

\section{Genetic characterization of the Cryptosporidium spp. at the SSU rRNA and gp60 loci}

Sequence analysis of 11 PCR products of the $S S U$ rRNA gene of Cryptosporidium indicated that all 11 samples were $C$. hominis. Furthermore, the obtained sequences represented five types with six polymorphic sites (Fig. 1). One SSU rDNA sequence representing seven Cryptosporidium isolates was identical to that of the C. hominis isolate derived from a rhesus macaque in Henan Province of China (GenBank: KF679722). The other four sequences (GenBank: MK270514-MK270517) had not been reported previously. These sequences had either one (position 528 or 760 ) or three (positions 475, 609 and 618 or 528,609 and 661) base variations compared with the sequence KF679722, which had the greatest similarity to the novel sequences obtained here. The first nucleotide of the reference sequence (KF679722) was considered to be position number one.

Cryptosporidium hominis-positive specimens were subtyped by sequence analysis of the gp60 gene. Of the $11 C$. hominis isolates obtained, nine were successfully amplified. Sequence analysis of the nine gp60 gene sequences suggested that they belong to three subtype families (Ia, Ii and Io). Four subtypes, IaA20R3a $(n=1)$, IoA17a $(n=1)$, IoA17b $(n=1)$ and $\operatorname{IiA17}(n=6)$, were

Table 1 Prevalence and distribution of Cryptosporidium species and subtypes in long-tailed macaque by age, sex and symptom

\begin{tabular}{llllll}
\hline Group & & No. examined & No. positive (\%) & Cryptosporidium species $(n)$ & Subtype $(n)$ \\
\hline Age & Young & 125 & $11(8.8)$ & C. hominis (11) & laA20R3a (1); loA17a (1); loA17b (1); liA17 (6) \\
& Adult & 68 & 0 & - & - \\
Sex & Female & 92 & $6(6.5)$ & C. hominis (6) & liA17 (4) \\
& Male & 101 & $5(5.0)$ & C. hominis (5) & laA20R3a (1); loA17a (1); loA17b (1); liA17 (2) \\
Symptom & Diarrhea & 29 & $4(13.8)$ & C. hominis (4) & laA20R3a (1); loA17a (1); loA17b (1); liA17 (1) \\
& Non-diarrhea & 164 & $7(4.3)$ & C. hominis (7) & liA17 (5)
\end{tabular}


detected in the present study based on the established nomenclature system of the gp60 subtypes. Among them, the novel subtypes IaA20R3a, IoA17a and IoA17b have not been reported previously. The sequence of subtype IaA20R3a (MK270518) has a maximum homology of $97 \%$ to isolate JF927196 which was isolated from Bangladeshi children. There were three nucleotide differences observed between IoA17a (MK270519) and IoA17b (MK270520). In addition, these isolates shared 98\% identity with the sequence (KX926459) of subtype IdA15 which was initially misdiagnosed, and has subsequently been renamed IoA15 [10]. The novel gp60 subtypes IaA20R3a, IoA17a and IoA17b showed the same rRNA type KF679722. Isolate IiA17 was identical to the sequence of a $C$. hominis gp60 subtype isolated from a rhesus macaque in Henan, China (HQ397716). The four novel rRNA types (MK270514-MK270517) showed the same gp60 subtype IiA17. Subtype IiA17 was isolated from feces in monkeys with diarrhea as well as the nondiarrhea group. In contrast, subtypes IaA20R3a, IoA17a and IoA17b were only detected in the diarrhea group.

\section{Discussion}

In the present study, Cryptosporidium hominis was only identified in $M$. fascicularis, with an overall prevalence of $5.7 \%(11 / 193)$. This observation is consistent with the report in captive $M$. mulatta from the Qinling Mountains (7.0\%) and lower than that reported in wild M. mulatta (10.9\%) from Guizhou, China [19, 21]. While the prevalence of Cryptosporidium in M. fascicularis observed here is higher than in other Chinese primates, another study of 26 NHP species by Karim et al. [20] observed Cryptosporidium was detected in 19 of the 2660 (0.7\%) faecal specimens tested from China. Interestingly, only four NHP species were infected with Cryptosporidium (0.7\% of rhesus macaques, $1.0 \%$ of cynomolgus monkeys, $10.0 \%$ of slow lorises and $6.7 \%$ of Francois' leaf monkeys). Low prevalence of Cryptosporidium was also reported in laboratory-reared cynomolgus monkeys $(0.5 \%)$ in Guangxi, China [22]. In addition, the prevalence of Cryptosporidium in M. fascicularis in the present study was higher than that reported for M. fascicularis in Thailand (1.0\%), mountain gorillas in Rwanda (4.0\%) and Uganda $(4.0 \%)$, in orangutans from Indonesia $(2.7 \%)$, in olive baboons from Kenya (2.6\%), and in western lowland gorillas from the Central African Republic (0.5\%) [16, $17,23-25,27]$. However, although the reported positivity rates were lower in wild primates conducted in other countries compared to the present study, NHPs from Tanzania exhibited much higher rates of infection than those observed here [26]. The differences in prevalence may be related to factors such as differences in regional environments, the sensitivity and specificity of detection methods, animal the health statuses of the animals at the time of sampling, and the overall sample size. We also observed that the infection rate of Cryptosporidium in M. fascicularis (5.7\%) was higher than that in M. mulatta $(0 \%)$. In consideration of this observation, as well as those mentioned above, the species of NHPs may reflect differences in susceptibility, which could explain the speciesto-species variation in prevalence. In fact, $64.8 \%$ of the $M$. fascicularis in the present study were less than one yearold, whereas all of the M. mulatta were over 10 years of age. For M. fascicularis, infection rates of young animals were higher than that of adult animals. These data suggest that age may be a risk factor in NHPs. In support of

\footnotetext{
KF679722 GTT AAA AAG CTC GTA GTT GGA TTT CTG TTA ATA ATT IAT ATA ATA TAT TTT GAT GAA TAT TTA TAT AAT ATT AAC ATA ATT CAT ATT ACT ATT TTT TTT 495 MK270516 GIT AAA AAG CTC GTA GTT GGA TIT CTG ITA ATA ATT TAT ATA ATA TAT TIT GAT GAA TAT TTA TAT AAT ATT AAC ATA ATT CAT ATT ACT ATT TTT TTT MK270515 GIT AAA AAG CTC GTA GIT GGA ITT CTG ITA ATA ATT IAT ATA ATA TAT ITT GAT GAA TAT TTA TAT AAT ATT AAC ATA ATT CAT ATT ACT ATT TIT TIT MK270517 GIT AAA AAG CTC GTA GTT GGA TTT CTG TTA ATA ATT TAT ATA ATA TAT TTT GAT GAA TAT TTA TAT AAT ATT AAC ATA ATT CAT ATT ACT ATT TIT TIT MK270514 GIT AAA AAG CTC GTA GTT GGA TTT CTG TTA ATA ATT TAT ATA ATA TAT TIT GAT GAA TAT TTA TAT AAT ATT AAC ATG ATT CAT ATT ACT ATT TTT TIT

KF679722 TAG TAT ATG AAA TTT TAC TTT GAG AAA ATT AFA GTG CTT AAA GCA GGC ATA TGC CTT GAA TAC TCC AGC ATG GAA TAA TAT TAA AGA TTT TTA TCT TTT 594 MK270516 TAG TAT ATG AAA TIT TAC TIT GAG AAA ATT A GE GTG CTT AAA GCA GGC ATA TGC CTT GAA TAC TCC AGC ATG GAA TAA TAT TAA AGA TTT TTA TCT TIT MK270515 TAG TAT ATG AAA TIT TAC TIT GAG AAA ATT APP GTG CIT AAA GCA GGC ATA TGC CTT GAA TAC TCC AGC ATG GAA TAA TAT TAA AGA TIT TTA TCT TTT MK270517 TAG TAT ATG AAA TIT TAC ITT GAG AAA ATT APA GTG CTT AAA GCA GGC ATA TGC CTT GAA TAC TCC AGC ATG GAA TAA TAT TAA AGA TIT TTA TCT TIT MK270514 TAG TAT ATG AAA TIT TAC TIT GAG AAA ATT AGA GTG CTT AAA GCA GGC ATA TGC CTT GAA TAC TCC AGC ATG GAA TAA TAT TAA AGA TTT ITA TCT TIT

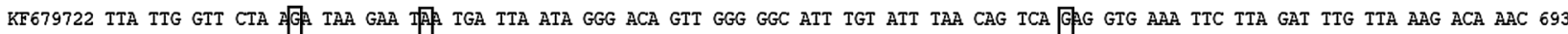
MK270516 TTA TTG GTT CTA AG TAA GAA IAP TGA TTA ATA GGG ACA GTT GGG GGC ATT TGT ATT TAA CAG TCA GAG GTG AAA TTC TTA GAT TTG TTA AAG ACA AAC MK270515 TTA TTG GIT CTA AG TAA GAA IAP TGA TTA ATA GGG ACA GTT GGG GGC ATT TGT ATT TAA CAG TCA GAG GTG AAA TTC TTA GAT ITG TTA AAG ACA AAC MK270517 TTA TTG GIT CTA AAP TAA GAA TAP TGA ITA ATA GGG ACA GTT GGG GGC ATT TGT ATT TAA CAG TCA AAG GTG AAA TTC TTA GAT TTG TTA AAG ACA AAC MK270514 TTA TTG GIT CTA AMA TAA GAA IGA TGA TTA ATA GGG ACA GIT GGG GGC ATT TGT ATT TAA CAG TCA GAG GTG AAA ITC TTA GAT TTG TTA AAG ACA AAC

KF679722 TAA TGC GAA AGC ATT TGC CAA GGA TGT TTT CAT TAA ICA AGA ACG AAA GTT AGG GGA TCG AAG ACF ATC AGA TAC CGT CGT AGT CTT AAC CAT AAA CTA 792 MK270516 TAA TGC GAA AGC ATT TGC CAA GGA TGT TTT CAT TAA ICA AGA ACG AAA GTT AGG GGA TCG AAG ACA ATC AGA TAC CGT CGT AGT CTT AAC CAT AAA CTA MK270515 TAA TGC GAA AGC ATT TGC CAA GGA TGT TTT CAT TAA ICA AGA ACG AAA GTT AGG GGA TCG AAG ACG ATC AGA TAC CGT CGT AGT CTT AAC CAT AAA CTA MK270517 TAA TGC GAA AGC ATT TGC CAA GGA TGT ITT CAT TAA TCA AGA ACG AAA GTT AGG GGA TCG AAG ACG ATC AGA TAC CGT CGT AGT CTT AAC CAT AAA CTA MK270514 TAA TGC GAA AGC ATT TGC CAA GGA TGT ITT CAT TAA ICA AGA ACG AAA GTT AGG GGA TCG AAG ACG ATC AGA TAC CGI CGT AGT CTT AAC CAT AAA CTA

Fig. 1 Sequence variation in the small subunit (SSU) rRNA gene among of C. hominis isolates. SSU rRNA sequences of one known type (GenBank: KF679722) and four novel types (GenBank: MK270514-MK270517) identified in this study were aligned. The first nucleotide of the reference sequence KF679722 was considered to be position number one
} 
this conclusion, another study has reported that infant baboons were infected at a higher rate (15.4\%) than that of adults (1.3\%) [15].

In the present study, only $C$. hominis was detected in M. fascicularis. Although there are other reports of Cryptosporidium spp. in non-human primates, few have provided detailed molecular information about these parasites in the great apes (Table 2) [15, 17-29]. Previous studies have indicated that at least eight species of Cryptosporidium have been reported in NHPs, including C. hominis, C. parvum, C. felis, C. muris, C. bovis, C. ubiquitum, C. meleagridis and C. andersoni. Among these, $C$. hominis was the most common Cryptosporidium species detected in NHPs $(80 / 120)$ (Table 2) [15, 1729]. The potential for zoonotic transmission is evident for the species and subtypes detected. C. hominis was the most common species in human cases of cryptosporidiosis in China, accounting for 48.3\% (127/263) of all cryptosporidiosis cases [32]. Although C. hominis is widely considered a human-specific pathogen, and humans are the only natural host, it is a rather common Cryptosporidium species detected in non-human primates, horses and donkeys [10]. Furthermore, C. hominis has recently been identified in cattle, yaks, sheep, goats, kangaroos, rodents, hedgehogs, dogs and dugong [10]. Experimental infections with $C$. hominis have been successful in Mongolian gerbils, piglets and mouse [33-35]. The true and natural host range of $C$. hominis needs to be confirmed by subsequent molecular data from epidemiological studies of Cryptosporidium.

Table 2 Prevalence and distribution of Cryptosporidium species and subtypes in natural infection of non human primates worldwide

\begin{tabular}{|c|c|c|c|c|c|}
\hline Country & Species of NHPs & $\begin{array}{l}\text { No. positive/ } \\
\text { no. examined } \\
(\%)\end{array}$ & Species $(n)$ & Subtype $(n)^{a}$ & Ref \\
\hline $\begin{array}{l}\text { Central } \\
\text { African } \\
\text { Republic }\end{array}$ & $\begin{array}{l}\text { Gorilla gorilla gorilla (western low- } \\
\text { land gorillas) }\end{array}$ & $1 / 201(0.5)$ & C. bovis (1) & - & {$[17]$} \\
\hline China & Saimiri sciureus (squirrel monkey) & 1 & C. hominis (1) & IkA7G4 $(1)^{b}$ & [18] \\
\hline China & Macaca mulatta (rhesus macaque) & $6 / 86(7.0)$ & C. andersoni (5); C. parvum (1) & IIA15G2R1 (1) & [19] \\
\hline China & Macaca mulatta (rhesus macaque) & $9 / 1316(0.7)$ & C. hominis (9) & IbA12G3 (7); PN (2) & [20] \\
\hline China & $\begin{array}{l}\text { Macaca fascicularis (long-tailed } \\
\text { macaque) }\end{array}$ & $8 / 778(1.0)$ & C. muris (4); C. hominis (4) & liA17 (1); PN (3) & [20] \\
\hline China & $\begin{array}{l}\text { Nycticebus bengalensis (Bengal slow } \\
\text { loris) }\end{array}$ & $1 / 10(10.0)$ & C. muris (1) & - & [20] \\
\hline China & $\begin{array}{l}\text { Presbytis francoisi (Francois’ leaf } \\
\text { monkey) }\end{array}$ & $1 / 15(6.7)$ & C. hominis (1) & pn & [20] \\
\hline China & Macaca mulatta (rhesus macaque) & 45/411 (10.9) & $\begin{array}{l}\text { C. hominis (39); C. parvum (5); C. } \\
\text { felis (1) }\end{array}$ & $\begin{array}{l}\text { laA13R7 (2); laA13R8 (6); laA14R7 (1); } \\
\text { IdA20 (10); leA11G3T3 (8); IfA16G2 } \\
\text { (1); IIcA5G3a (5) }\end{array}$ & [21] \\
\hline China & $\begin{array}{l}\text { Macaca fascicularis (long-tailed } \\
\text { macaque) }\end{array}$ & $1 / 205(0.5)$ & C. hominis (1) & $\operatorname{ldA14}(1)$ & [22] \\
\hline Indonesia & $\begin{array}{l}\text { Pongo abelii; Pongo pygmaeus } \\
\text { (orangutans) }\end{array}$ & $8 / 298(2.7)$ & C.parvum (2); C. muris (6) & - & [23] \\
\hline Kenya & Papio anubis (olive baboon) & $6 / 235(2.6)$ & C. hominis (6) & IfA12G2 (2); IbA9G3 (2); IiA14 (1) & [15] \\
\hline Rwanda & $\begin{array}{l}\text { Gorilla beringei beringei (mountain } \\
\text { gorilla) }\end{array}$ & $4 / 100(4.0)$ & C. muris (2); C. meleagridis (2) & - & [24] \\
\hline Thailand & $\begin{array}{l}\text { Macaca fascicularis (long-tailed } \\
\text { macaque) }\end{array}$ & $2 / 200(1.0)$ & C. hominis (2) & - & [25] \\
\hline Tanzania & Papio anubis (olive baboon) & $5 / 47(10.6)$ & C. hominis (5) & IfA12G2 (3/5) & [26] \\
\hline Tanzania & Pan troglodytes (chimpanzee) & $12 / 58(20.7)$ & C. hominis (7); C. suis (6) & IfA12G2 (2/7) & [26] \\
\hline Tanzania & Pan troglodytes (chimpanzee) & $4 / 26(15.4)$ & C. hominis (4) & IfA12G2 (3/4) & [26] \\
\hline Uganda & $\begin{array}{l}\text { Gorilla beringei beringei (mountain } \\
\text { gorilla) }\end{array}$ & $4 / 100(4.0)$ & C. parvum (4) & - & [27] \\
\hline USA & $\begin{array}{l}\text { Propithecus coquereli (Coquerel's } \\
\text { sifaka) }\end{array}$ & 1 & C. suis (1) & - & [28] \\
\hline USA & Macaca mulatta (rhesus macaque) & 1 & C. hominis (1) & liA17 & [29] \\
\hline
\end{tabular}

a The numbers of subtypes are not consistent with the positives of $C$. hominis in some countries because not all isolates were genotyped successfully

b Subtype IKA7G4 was misnamed

Abbreviations: Ref, reference; pn, PCR-negative; -, not subtyping or no subtypes 
To date, more than 10 subtype families have been recognized in $C$. hominis based on sequence analysis of the gp60 gene; six of these subtype families (Ia, Ib, Id, Ie, If and Ii) have been identified in NHPs (Table 2) [15, 17-29]. Subtype families Ia, Ib, Id and Ie account for the majority of worldwide cases in humans [10]. In the present study, three subtype families (Ia, Io, and Ii) were identified, and were composed of IaA20R3a, IoA17a, IoA17b and IiA17. Among them, subtype IiA17 was the dominant subtype (66.7\%) which has been reported in a rhesus monkey from the USA, in a crab-eating macaque from China, and two humans from Sweden who had visited a monkey farm in Thailand [20,29, 36]. The subtypes IaA20R3a, IoA17a and IoA17b identified here have not been reported to the best of our knowledge, thus representing new subtypes. The subtype family Ia is common in humans from China, and IaA14R4 was the cause of a cryptosporidiosis outbreak in a pediatric ward in Shanghai [37]. In fact, C. hominis Ia subtype families have also been detected at high frequencies in rhesus monkeys from Guizhou, China. Thus, NHPs can play a potential role in zoonotic transmission of $C$. hominis in China [21]. Also of concern, the gp60 subtype family Io, and the related Id, have been identified in two horses in China [38]. The new subtypes IoA17a and IoA17b found in $M$. fascicularis here, is possibly a reflection of endemic transmission of $C$. hominis in these animals. The true subtype constitutions of $C$. hominis in M. fascicularis need to be confirmed by more systematic epidemiological studies of Cryptosporidium from these animals in the future.

\section{Conclusions}

In this study, we determined the prevalence rate of $C$. hominis among $M$. fascicularis in a breeding base of experimental primates in Hainan Island of China. The novel subtypes of $C$. hominis detected in $M$. fascicularis might present the endemic genetic characterization of population structure of Cryptosporidium, although the genetic diversity among $C$. hominis subtypes is not well understood. To better evaluate the transmission of Cryptosporidium from M. fascicularis to humans, more studies investigating the biology, population genetics and transmission dynamics of Cryptosporidium in $M$. fascicularis throughout different geographical regions are needed.

\section{Abbreviations}

NHPs: non-human primates; PCR: polymerase chain reaction; gp60: 60-kilodalton glycoprotein; SSU rRNA: small subunit of nuclear ribosomal RNA; HIV: human immunodeficiency virus; AIDS: Acquired Immunodeficiency Syndrome; NIH: National Institutes of Health; FAO: Food and Agriculture Organization; WHO: World Health Organization.
Acknowledgements

Not applicable.

\section{Funding}

This work was supported partially by the Innovation Research Team Project of Hainan Natural Science Foundation (2018CXTD340) and the National Natural Science Foundation of China (No. 81672072 and No. 81760378). The funders had no role in study design, data collection and interpretation, or the decision to submit the work for publication.

\section{Availability of data and materials}

The novel representative sequences of $C$. hominis identified in this study were submitted to the GenBank database under the accession numbers MK270514MK270517 (18S rRNA gene), and MK270518-MK270520 (gp60 gene).

\section{Authors' contributions}

Designed and conceived the research: WZ and GL. Collected samples: WZ, H-H Z, M-Y Q, M-C L and L-H L. Performed experiments: WZ and H-H Z. Analysis and interpretation: WZ. Contributed reagents, materials and/or analysis tools: H-R J, F-F Y. Wrote the paper: WZ. Revised the paper: JF-W C. Grant funding: GL. All authors read and approved the final manuscript.

\section{Ethics approval and consent to participate}

Prior to the initiation of the study, the farm owners were contacted, and permission to sample the animals was obtained. Rather than handling the animals directly, fecal samples were instead collected in order to minimize discomfort and stress to the animals. No animals were harmed in any way during the course of the study.

\section{Consent for publication}

Not applicable.

\section{Competing interests}

The authors declare that they have no competing interests.

\section{Publisher's Note}

Springer Nature remains neutral with regard to jurisdictional claims in published maps and institutional affiliations.

\section{Author details}

${ }^{1}$ Department of Pathogenic Biology, Hainan Medical University, Haikou, Hainan, China. ${ }^{2}$ Hainan Medical University-The University of Hong Kong Joint Laboratory of Tropical Infectious Diseases, Hainan Medical University, Haikou, Hainan, China. ${ }^{3}$ Key Laboratory of Translation Medicine Tropical Diseases, Hainan Medical University, Haikou, Hainan, China. ${ }^{4}$ Hainan Jingang Biological Technology Co., Ltd., Haikou, Hainan, China. ${ }^{5}$ Department of Microbiology, Li Ka Shing Faculty of Medicine, The University of Hong Kong, Pokfulam, Hong Kong Special Administrative Region, China.

Received: 6 January 2019 Accepted: 19 April 2019

Published online: 30 April 2019

\section{References}

1. Checkley W, White AC Jr, Jaganath D, Arrowood MJ, Chalmers RM, Chen $\mathrm{XM}$, et al. A review of the global burden, novel diagnostics, therapeutics, and vaccine targets for Cryptosporidium. Lancet Infect Dis. 2015;15:85-94.

2. Colford JM, Tager IB, Hirozawa AM, Lemp GF, Aragon T, Petersen C. Cryptosporidiosis among patients infected with human immunodeficiency virus. Factors related to symptomatic infection and survival. Am J Epidemiol. 1996;144:807-16.

3. GBD Diarrhoeal Diseases Collaborators. Estimates of global, regional, and national morbidity, mortality, and aetiologies of diarrhoeal diseases: a systematic analysis for the Global Burden of Disease Study 2015. Lancet Infect Dis. 2017;17:909-48.

4. Ryan U, Hijjawi N. New developments in Cryptosporidium research. Int J Parasitol. 2015:45:367-73. 
5. Chalmers RM, Giles M. Zoonotic cryptosporidiosis in the UK-challenges for control. J Appl Microbiol. 2010;109:1487-97.

6. Efstratiou A, Ongerth JE, Karanis P. Waterborne transmission of protozoan parasites: review of worldwide outbreaks - an update 2011-2016. Water Res. 2017;114:14-22.

7. Ryan U, Hijjawi N, Xiao L. Foodborne cryptosporidiosis. Int J Parasitol. 2018:48:1-12

8. NIAID Emerging Infectious Diseases/Pathogens. (https://www.niaid.nih. gov/research/emerging-infectious-diseases-pathogens). Accessed 10 Dec 2018.

9. Report of a Joint FAO/WHO Expert Meeting, 3-7 September 2012, FAO Headquarters, Rome, Italy. (http://www.fao.org/food/food-safety-quali ty/a-zindex/foodborne-parasites/en/). Accessed 10 Dec 2018.

10. Feng Y, Ryan UM, Xiao L. Genetic diversity and population structure of Cryptosporidium. Trends Parasitol. 2018;34:997-1011.

11. Khan A, Shaik JS, Grigg ME. Genomics and molecular epidemiology of Cryptosporidium species. Acta Trop. 2018;184:1-14.

12. Xiao L, Feng Y. Molecular epidemiologic tools for waterborne pathogens Cryptosporidium spp. and Giardia duodenalis. Food Waterborne Parasitol. 2017;8-9:14-32.

13. Chalmers RM, Smith RP, Hadfield SJ, Elwin K, Giles M. Zoonotic linkage and variation in Cryptosporidium parvum from patients in the United Kingdom. Parasitol Res. 2011;108:1321-5.

14. Cacciò SM, Sannella AR, Mariano V, Valentini S, Berti F, Tosini F, et al. A rare Cryptosporidium parvum genotype associated with infection of lambs and zoonotic transmission in Italy. Vet Parasitol. 2013;191:128-31.

15. Li W, Kiulia NM, Mwenda JM, Nyachieo A, Taylor MB, Zhang X, et al. Cyclospora papionis, Cryptosporidium hominis, and human-pathogenic Enterocytozoon bieneusi in captive baboons in Kenya. J Clin Microbiol. 2011:49:4326-9.

16. Kváč M, McEvoy J, Stenger B, Clark M. Cryptosporidiosis in other vertebrates. In: Cacciò SM, Widmer G, editors. Cryptosporidium: parasite and disease. Vienna: Springer; 2014. p. 237-323.

17. Sak B, Petrzelkova KJ, Kvetonova D, Mynarova A, Shutt KA, Pomajbikova $\mathrm{K}$, et al. Long-term monitoring of microsporidia, Cryptosporidium and Giardia infections in western Lowland Gorillas (Gorilla gorilla gorilla) at different stages of habituation in Dzanga Sangha Protected Areas, Central African Republic. PLoS ONE. 2013:8:e71840.

18. Liu X, Xie N, Li W, Zhou Z, Zhong Z, Shen L, et al. Emergence of Cryptosporidium hominis monkey genotype II and novel subtype family $\mathrm{k}$ in the squirrel monkey (Saimiri sciureus) in China. PLoS ONE. 2015;10:e0141450.

19. Du SZ, Zhao GH, Shao JF, Fang YQ, Tian GR, Zhang LX, et al. Cryptosporidium spp., Giardia intestinalis, and Enterocytozoon bieneusi in captive non-human primates in Qinling Mountains. Korean J Parasitol. 2015;53:395-402.

20. Karim MR, Zhang S, Jian F, Li J, Zhou C, Zhang L, et al. Multilocus typing of Cryptosporidium spp. and Giardia duodenalis from non-human primates in China. Int J Parasitol. 2014;44:1039-47.

21. Ye J, Xiao L, Ma J, Guo M, Liu L, Feng Y. Anthroponotic enteric parasites in monkeys in public park, China. Emerg Infect Dis. 2012;18:1640-3.

22. Ye J, Xiao L, Li J, Huang W, Amer SE, Guo Y, et al. Occurrence of humanpathogenic Enterocytozoon bieneusi, Giardia duodenalis and Cryptosporidium genotypes in laboratory macaques in Guangxi, China. Parasitol Int. 2014;63:132-7.

23. Mynářová A, Foitová I, Kváč M, Květoňová D, Rost M, Morrogh-Bernard $\mathrm{H}$, Nurcahyo W, et al. Prevalence of Cryptosporidium spp., Enterocytozoon bieneusi, Encephalitozoon spp. and Giardia intestinalis in wild, semi-wild and captive orangutans (Pongo abelii and Pongo pygmaeus) on Sumatra and Borneo, Indonesia. PLoS ONE. 2016;11:e0152771.

24. Sak B, Petrželková KJ, Květoňová D, Mynářová A, Pomajbíková K, Modrý D, et al. Diversity of microsporidia, Cryptosporidium and Giardia in mountain gorillas (Gorilla beringei beringei) in Volcanoes National Park, Rwanda. PLoS ONE. 2014;9:e109751.
25. Sricharern W, Inpankaew T, Keawmongkol S, Supanam J, Stich RW, Jittapalapong S. Molecular detection and prevalence of Giardia duodenalis and Cryptosporidium spp. among long-tailed macaques (Macaca fascicularis) in Thailand. Infect Genet Evol. 2016;40:310-4.

26. Parsons MB, Travis D, Lonsdorf EV, Lipende I, Roellig DM, Collins A, et al. Epidemiology and molecular characterization of Cryptosporidium spp. in humans, wild primates, and domesticated animals in the Greater Gombe Ecosystem, Tanzania. PLoS Negl Trop Dis. 2015;9:e0003529.

27. GraczykTK, DaSilva AJ, Cranfield MR, Nizeyi JB, Kalema GR, Pieniazek NJ. Cryptosporidium parvum genotype 2 infections in free-ranging mountain gorillas (Gorilla gorilla beringei) of the Bwindi Impenetrable National Park, Uganda. Parasitol Res. 2001;87:368-70.

28. da Silva AJ, Cacciò S, Williams C, Won KY, Nace EK, Whittier C, et al. Molecular and morphologic characterization of a Cryptosporidium genotype identified in lemurs. Vet Parasitol. 2003;111:297-307.

29. Feng Y, Lal AA, Li N, Xiao L. Subtypes of Cryptosporidium spp. in mice and other small mammals. Exp Parasitol. 2011;127:238-42.

30. Xiao L, Escalante L, Yang C, Sulaiman I, Escalante AA, Montali RJ, et al. Phylogenetic analysis of Cryptosporidium parasites based on the smallsubunit rRNA gene locus. Appl Environ Microbiol. 1999;65:1578-83.

31. Alves M, Xiao L, Sulaiman I, Lal AA, Matos O, Antunes F. Subgenotype analysis of Cryptosporidium isolates from humans, cattle, and zoo ruminants in Portugal. J Clin Microbiol. 2003;41:2744-7.

32. Feng Y, Xiao L. Molecular epidemiology of Cryptosporidiosis in China. Front Microbiol. 2017;8:1701.

33. Baishanbo A, Gargala G, Delaunay A, François A, Ballet JJ, Favennec L. Infectivity of Cryptosporidium hominis and Cryptosporidium parvum genotype 2 isolates in immunosuppressed Mongolian gerbils. Infect Immun. 2005:73:5252-5.

34. Roche JK, Rojo AL, Costa LB, Smeltz R, Manque P, Woehlbier U, et al. Intranasal vaccination in mice with an attenuated Salmonella enterica Serovar 908htr A expressing Cp15 of Cryptosporidium: impact of malnutrition with preservation of cytokine secretion. Vaccine. 2013;31:912-8.

35. Lee S, Ginese M, Beamer G, Danz HR, Girouard DJ, Chapman-Bonofiglio $S P$, et al. Therapeutic efficacy of bumped kinase inhibitor 1369 in a pig model of acute diarrhea caused by Cryptosporidium hominis. Antimicrob Agents Chemother. 2018;62:e00147-218.

36. Lebbad M, Winiecka-Krusnell J, Insulander M, Beser J. Molecular characterization and epidemiological investigation of Cryptosporidium hominis IKA18G1 and C. hominis monkey genotype liA17, two unusual subtypes diagnosed in Swedish patients. Exp Parasitol. 2018;188:50-7.

37. Feng $Y$, Wang L, Duan L, Gomez-Puerta LA, Zhang L, Zhao X, et al. Extended outbreak of cryptosporidiosis in a pediatric hospital, China. Emerg Infect Dis. 2012;18:312-4.

38. Deng L, Li W, Zhong Z, Gong C, Cao X, Song Y, et al. Occurrence and genetic characteristics of Cryptosporidium hominis and Cryptosporidium andersoni in horses from southwestern China. J Eukaryot Microbiol. 2017;64:716-20.

Ready to submit your research? Choose BMC and benefit from:

- fast, convenient online submission

- thorough peer review by experienced researchers in your field

- rapid publication on acceptance

- support for research data, including large and complex data types

- gold Open Access which fosters wider collaboration and increased citations

- maximum visibility for your research: over $100 \mathrm{M}$ website views per year

At $\mathrm{BMC}$, research is always in progress.

Learn more biomedcentral.com/submissions 